\title{
Embodied health practices: The use of Traditional Healing and Conventional Medicine in a North Norwegian Community
}

\author{
PhD-fellow Mona Anita Kiil \\ Department of Clinical Medicine, Faculty of Health Sciences, \\ University of Tromso-The Arctic University of Norway \\ E-mail: mona.kiil@uit.no
}

\section{Dr. Anita Salamonsen}

National Research Center in Complementary and Alternative Medicine, Department of Community Medicine, Faculty of Health Sciences, University of Tromso - The Arctic University of Norway

E-mail: anita.salamonsen@uit.no

Doi:10.5901/ajis.2013.v2n3p483

\begin{abstract}
Scandinavian welfare states like Norway represent a cultural context in which citizens who become ill are supposed to trust and receive health care within the conventional health care system that is officially subsidized and based on biomedical knowledge. Despite this officially initiated health practice, unofficial and non-commercial health practices exist in many North Norwegian communities, consisting of traditional healers which people actively use or would consider to use when facing illness or crisis. The municipality of Nordreisa in Northern Troms is commonly described as "where the three tribes meet"- the "tribes" being the indigenous Sami people, the Kven, descendants of Finnish immigrants, and the majority population of the Norwegians - and for this reason the region has historically been considered a cultural melting pot. The eight participants in this ethnographic study, recruited from an outpatient mental health care clinic in Nordreisa, find themselves positioned as users of both traditional healing practices and the conventional mental health care offered by the clinic. The aim of this article is to explore mental ill patients' reasons for, and experiences from, the use of traditional healing as well as the conventional health care system within this cultural context by applying theories of trust and embodiment on important empirical patterns of illness behavior. The participants experienced being-and juggling-between the two significantly different medical and cultural systems. In our perspective, these patients' use of both systems can be understood as "embodied health practices", based on different cultural approaches to health, healing and knowledge, and thus, barriers of embodied health care practices and trust may cause problems in the encounters between mentally ill patients and their treatment providers. The participants experienced vulnerability and expressed lack of trust in the conventional mental health care in regards to how their traditional healing practices were understood. Furthermore, they feared being diagnosed with more severe mental health disorders within the conventional health care system than if they under-communicated their trust in and use of traditional healing. We argue that the understanding of "embodied trust" introduced in this article may add important new perspectives on complex contemporary healing contexts and healing practices.
\end{abstract}

\section{Introduction}

The social cartography of health and health care differs across cultures and history (Adams, Andrews, Barnes, Broom, \& Magin, 2012). Scandinavian welfare states like Norway represent a cultural context in which citizens who become ill are supposed to trust and receive health care within the conventional health care system that is officially subsidized (Bergh \& Bjørnskov, 2011). The Scandinavian welfare state model is characterized by universal rights and equality based on governmental re-distribution of taxation revenue. In this model, the conventional health care systems are funded by the health authorities and based on scientific biomedical knowledge as a basis for problem solving (Kuhnle, 1999). Despite this politically initiated illness behavior, an unknown percent of patients in Northern Norway turn to traditional healers who they actively use or would consider using when facing illness or crisis. Traditional healers are non-professional and noncommercial therapists who are closely connected to the local culture and world-views (Kiil, 2013).

The region of Northern Troms in Northern Norway is a crossing-point between what has commonly been described 
as "the three tribes"- which includes the indigenous Sami people, the Kven, who are descendants of Finnish immigrants to the area, and the majority population of the Norwegians-and for this reason the region has historically been considered a cultural melting pot. Despite this obvious cultural diversity, the notion of culture is somewhat problematic and connected to ambiguities - particularly concerning the Sami identity, which has suffered due to the policies by the Norwegian State in the after-match of the second World War to assimilate the indigenous people. Nevertheless, this diversity is expressed through a widespread use of traditional healing practices such as reading. Reading is commonly known as being a form of spiritual guidance and support during times of illness, where the reader-sometimes among others actions- is speaking biblical words with the intention to heal. It is not the actual words that heal, but the power of God that comes with it (Kiil, 2013).

In addition, we know that over 40 percent of Norwegians pay out-of-pocket for treatment alternatives found within the field of complementary and alternative medicine (CAM) (Fønnebø, 2013). The borders between CAM and conventional health care are unclear and changing, but CAM therapies often have in common that they are based on experience-based knowledge and the principles of holism and vitalism (Coulter \& Willis, 2007). In many studies, traditional healing would be defined as CAM (Kristoffersen et al., 2008), but in our understanding, this is not a correct definition based on our understanding of CAM as commercial health care practices offered to the public outside the Norwegian conventional health care system, such as acupuncture, massage, and homeopathy (Adams, Andrews, Barnes, Broom, \& Magin, 2012).

The Norwegian conventional health care system can be perceived as a context of patients' use of traditional healing as well as their use of CAM, as the participants in this study who relate to traditional healers at the same time also receive treatment within the conventional health care system and thus relate to biomedical knowledge (Salamonsen et al., 2012; Salamonsen, 2013). The content and meaning of this combined use of non-conventional and conventional health practices is an interesting and so far under-explored issue of contemporary health practices.

\section{The aim of the study}

This article takes its point of departure in an empirical study of the use of traditional healers and the conventional health care system among a sample of North Norwegian patients diagnosed with mental illness and recruited within a conventional health care setting. Trust in health care systems and health care providers, as well as culturally based healing practices, seem to be important aspects of these patients' illness behavior. Thus, in this article, we develop a theoretical thinking of trust connected to an anthropological approach to embodiment in an analysis of these central empirical patterns of the study. The overall aim of this article is to extend our understanding of patients' reasons for, and experiences from, self-initiated and culturally based health practices based on a theoretical contribution to the field.

\section{Material, Methods \& Ethical Considerations}

\subsection{Material}

The conventional outpatient clinic for mental health in Northern Troms treats more than four hundred patients a year. About half of these patients live in the municipality of Nordreisa, where the clinic is situated, while the remaining have residency in the neighbouring municipalities of Skjervøy, Kåfjord and Kvænangen. The empirical study referred to in this article is an ethnographic fieldwork conducted in Nordreisa throughout the year of 2011 among eight patients who used the outpatient mental health care clinic for Northern Troms. The material mainly consists of repeated in-depth interviews and participant observation. In total, 17 interviews have been conducted, in addition to a number of conversations with readers, therapists and staff at the clinic and people in the local communities and also locals living outside of the region. The participants were between the ages of 22-74 and represented both genders. The participants were sampled on the basis of their interest in participating in the project and not by any specific diagnostic criteria. Regardless of this, all participants had been diagnosed with anxiety and/or depression.

\subsection{Methods \& Methodology}

Under-researched and experience-based issues like those explored here demand a flexible and open-ended research design, and thus a qualitative approach was chosen. An explorative, qualitative approach was also suited to develop knowledge that could generate empirically and theoretically based hypotheses for further research on this underexplored 
issue (Gobo, 2008). In-depth interviews were conducted by the first author of this article. They had an open-ended, yet semi-structured character, where a topic guide was used to direct the conversation to relevant topics regarding the patient's experiences. The strength with semi-structured interviews is thus that they help produce specific answers to questions of concern (Spradley, 1980; Kvale, 2001). A large part of these informal conversations can be defined as "ethnographic interviews", which are interviews where one just lets "information emerge" without necessarily pre-made questions, pen and paper. The flexibility of this approach makes it easier to have spontaneous interviews whenever the opportunity arises (Blaikie, 2000).

The interpersonal interaction that arose during the interviews particularly and the fieldwork generally, contributed to the production of knowledge and also new problems for discussion. This can also be referred to as a symbolic interaction and when analyzing the data material it is therefore important to focus on the production of meaning as well as the production of content (Järvinen, 2005; Kvale, 2001). Mishler (1986, p. 65) describes how both parts "strive to arrive at meanings together that both can understand".

Patients' experiences, decision-making, and reflections create the basis of this article. Experience can, from an inter-actionist perspective, be understood as a contextual concept that embraces the relationship between the person and her physical and social contexts. There is no experience without a subject who experiences and a process of experiencing. The process of experiencing is, however, not only private or subjective. One can say that it is about sharing experiences where the social context is incorporated by the experiencing subject. Such an understanding of the concept of experience is inspired by theorists such as Schütz and especially Dewey as: "they both take the social and intersubjective world of human agency as the point from which a notion of experience should be developed" (Grøn 2004, p. 109). Knowledge through experience is the knowledge people acquire through their everyday life, as opposed to expert competence, which consists of different professions' expertise. Applying knowledge that has been gained through experience is classified by Järvinen and Mik-Meyer (2006) as problem identification of a more intuitive kind when compared to how experts approach solutions. Based on their different competences, the positions where we find the different agents within a field are constructed and maintained. In this case, the agents are patients who are medically diagnosed with mental illness and positioning themselves as users of traditional healers as well as conventional medicine within a complex and culturally influenced therapeutic landscape in Northern Norway.

\subsection{Ethical considerations}

The study has received approval by the Regional Ethical Committee. All names of persons have been given pseudonyms, and personal identification factors have been altered. Vulnerability was an important ethical concern faced in the fieldwork, as patients diagnosed with mental illness may be perceived as potentially vulnerable people. The researcher should be prepared to meet seriously ill patients, which will require ethical considerations such as assessing whether an interview should be hold, in what way and whether all planned questions can be asked. Overall, the interviews were conducted with sensitivity to the needs and abilities of each of the participants (Rose, 1994). Another important ethical concern in the fieldwork was how cultural background and values participate and influence directly or indirectly the way the participants respond, and sometimes also influence their lives. This was a challenge contrary to typical clinical projects where the researcher can relate solely to technical equipment or at least can have a more mechanical approach to the field. This project consisted of exclusively human beings, their stories and the human interaction. On an ethical level this distinction is crucial, and has often been mentioned in studies (Wagner 1993; de Vries, Anderson \& Martinson 2006) where so-called soft methods have been used in traditionally "hard" fields such as medicine and clinical practice.

\section{Empirical Patterns and Analysis}

The patients' stories revealed layers of stories connected to the narrative of Nordreisa, the small community in Northern Troms where the outpatient clinic is situated. The empirical patterns of the material which this article is based on, show an ambiguous historical context which has created a certain framework for understanding the patient's use of both the conventional health care and traditional healing practices, and how the users of this outpatient clinic in Northern Troms thus experience being between, as well as juggling between these two significantly different medical and cultural systems. In the participants stories, the notion of trust, on different levels, were central.

On the positive side, however, this culturally complex region also constitutes communities of non-commercial care. The analysis revealed traditional healing practices that are part of a great network of informal healthcare that give help to 
people in crisis on several levels and without any economic compensation. This type of health care should therefore be viewed as complement to the treatment offered by the clinic in question.

With respect to treatment providers, the participants expressed that "trust must be earned", irrespective of the treatments' or treatment providers' status as conventional or non-official. All in all, the notion of trust, on different levels, constitutes a central empirical pattern in the material. Another important empirical pattern is differing understandings of illness in different contexts. Thus, in the following theoretically based analysis, we will draw on theories of sense-making and illness (Antonovsky, 1987; trust (Rowe \& Calnan, 2006; Scambler \& Britten, 2001) and embodiment (Csordas, 1990; 1999a; 1999b; Grøn, 2004; Salamonsen et al., 2012).

\subsection{Embodied healing epistemologies}

We argue that the participants in this study have different healing epistemologies embodied, and that this may be understood in terms of sense- making, embodiment and trust. Illness reaches deep into our lives, raising questions and interpretations that move beyond scientific explanations. Illness is related to how we live our lives, and how we look at existence and knowledge production (Antonovsky, 1987). The concept of illness seems to have certain shortcomings and might alienate them from their understandings of health and the make-up of every-day life. Through the patients` stories, there seem to be a pattern or an understanding of mental illness as interwoven in everyday life for people in this region. It appears like an inescapable fact, both due to the historical context of the community as well as to how history has shaped and still is shaping and dividing the community as of today. As such, one could say that poor mental health seems to be embodied in the inhabitants through the social memory of this community. The notion of trust is therefore crucial, and in constant negotiation between patient's and the various therapist's in the region.

We find Thomas Csordas' approach to bodily experiences and embodiment (Csordas 1990,

1999a, 1999b) relevant for use in a theory-based analysis of embodied health practices and trust in this article. Csordas' approach to embodiment is developed from the perspective of psychological anthropology, and leans strongly in the direction of the phenomenology of Merleau-Ponty (Csordas 1990). This perspective of experience and action is also inspired by social constructivism and semiotic perspectives, and focuses on actor, meaning, and action (Grøn 2004). Csordas (1999b) emphasizes the importance of making a distinction between "body" and "embodiment":

If embodiment is an existential condition in which the body is the subjective source or intersubjective ground of experience, then studies under the rubric of embodiment are not "about" the body per se. Instead they are about culture and experience insofar as these can be understood from the standpoint of bodily being-in-the-world. (p.143)

He also argues that embodiment is the existential ground of culture and self:

The central issue is the manner in which the body is an existential condition of life - of course we have bodies, but there are multiple modes of embodiment, and it is the modulations of embodiment that are critical for the understanding of culture (pp. 181-182).

We can say that access to embodiment takes place through action, increased bodily awareness, and a verbalizing of bodily experiences and knowledge. Bodily awareness is here understood as the process through which people give discursive attention to the body in various cultural contexts. The body is perceived as a "body self", i.e. body and mind are mutually connected in a dialectical relationship (Csordas, 1999a; Salamonsen et al., 2012).

\subsection{Trust in health care}

In the participants' stories, the notion of trust, on different levels, was central. Trust does in many ways correlates with how one understands illness. The concept of trust is closely linked to the concepts "uncertainty" and "risk" (Alaszewski \& Brown, 2007, Rowe \& Calnan, 2006). We here base our analysis on an understanding such as the one described by Rowe and Calnan (2006, p. 4):

"The need for interpersonal trust relates to the vulnerability associated with being ill, the information asymmetries arising from the specialist nature of medical knowledge, and the uncertainty and element of risk regarding the competence and intentions of the practitioner on whom the patient is dependent. Without trust patients may well not access services at all, let alone disclose all medically relevant information. Trust is also important at an institutional level, as trust in particular 
hospitals, insurers and health care systems may affect patient support for and use of services and thus their economic and political viability."

Trust can be perceived as fundamental in the provision of healthcare. Patients' presupposed trust in the Norwegian health care system (Berg \& Bjørnskov, 2011; Holmboe et al., 2011) is under threat from a number of different sources as seen from a social science point of view (Scambler \& Britten, 2001). One is the rise in consumerism and the shift from organized to disorganized capitalism and cultural pluralism which has permeated the use of healthcare. The second is connected to the shift towards a post-modern culture in which science, including biomedicine, on which the Norwegian conventional health care system is based, has been deprivileged with active trust and citizenship becoming a more common feature of critical modern reasoning and professional expertise becoming increasingly contested. A third concern is the decline in the status of modern medicine (Scambler and Britten, 2001).

\subsection{Embodied trust}

We here introduce a theoretical perspective on "trust as embodied" in our analysis of the culturally influenced health practices under investigation. The concept of "embodied trust" has so far usually been used in religious settings, understood as trusting Gods' will with ones' physical body (the crossing of the Red Sea is a classic example). Here, we argue for an understanding of "embodied trust" understood the way Csordas outlines studies of embodiment; as studies about culture and experience insofar as these can be understood from the standpoint of bodily being-in-the-world (Csordas 1999b, p.143).

The traditional healing practices found in "the cultural melting pot" of Nordreisa will according to Arthur Kleinman's (1980) model of health and care systems belong to the folk sector, where one can find non-professional therapists who are closely connected to the local culture and world-view. We argue that the use of traditional healers in Nordreisa can be viewed as an embodied healing practice, based on embodied trust in the readers transformed within families and the local culture. The use of the conventional health care system, or in Kleimans' terms; "the professional sector" (Kleinman, 1980) can be viewed as something new and strange in this epistemological and historical context. It can also, however, be interpreted as an embodied health practice in Norwegian patients, because Norwegians grow up learning that citizens who become ill are supposed to trust and receive health care within the conventional health care system (Bergh \& Bjørnskov, 2011). Studies show that most Norwegians do so, even if they trust the conventional health care system less than citizens in many other comparable countries (Holmboe et al., 2011). Thus, both the participants' use of traditional healers and their use of the conventional health care system can be understood based on our theory of embodied trust.

\subsection{Barriers of trust}

We have argued that the use of traditional healers among the participants in the study can be viewed as an embodied healing practice, based on embodied trust in the traditional healers transformed within families and the local culture. Experiencing mental illness or crisis can be interpreted as a way for the participants to feel at home in their own stories (Kiil, 2013). Thus, the use of traditional healing can represent an embodied health strategy which makes this kind of illness more manageable and also creates order and continuity. Furthermore, we have argued that among Norwegian citizens, there may exist both a politically initiated and officially established trust as well as an embodied trust in the conventional health care system. This "embodied system trust" is based on the roots and implementation of the Scandinavian welfare state in the everyday life of Norwegian citizens. However, we pose that the participants in this study may trust the conventional health care system less than patients with other, less stigmatizing diagnoses. As users of traditional healing, these participants expressed that they experienced vulnerability in their encounters with the conventional health care system. Hence, they expressed lack of trust in the conventional health care system in regards to how their traditional, embodied healing practices were being understood. Furthermore, they feared being diagnosed with more severe mental health disorders than if they under-communicated their personal healing philosophies. These various barriers if trust can be caused by the professional interpretation of traditional understandings to healing pathways in communities with complex and co-existing healing practices like Nordreisa in Northern Norway.

\section{Concluding Remarks}

In this article, we introduce the concept "embodied trust" as a way to add new knowledge to the use of conventional medicine and traditional healing in a community characterized as "a cultural melting pot". We argue that this theoretical 
perspective adds information about important aspects of mentally ill patients' embodied healing practices including possible barriers of trust. "Embodied trust" as a theoretical approach to analyze illness behavior should be further developed to extend our understandings of the complexity of contemporary healing contexts and healing practices.

\section{References}

Adams, J., Andrews, G. J., Barnes, J., Broom, A., \& Magin, P. (2012). Introduction. In Adams, J. et al. (Eds.). Traditional, complementary and integrative medicine. An international reader. Hampshire: Palgrave Macmillan.

Alaszewski, A. \& Brown, P. (2007). Risk, uncertainty and knowledge. Health, Risk \& Society, 9(1), 1-10.

Antonovsky, A. (1987). Unraveling the mystery of health: How people manage stress and stay well. San Francisco: Jossey-Bass.

Bergh, A. \& Bjørnskov, C. (2011). Historical trust levels predict the current size of the welfare state. KYKLOS, 64(1), 1-19.

Blaikie, N. 2000: Designing Social Research. Cambridge: Polity Press.

Coulter, I. \& Willis, E. (2007). Explaining the growth of complementary and alternative medicine. Health Sociology Review, 16(3-4), 214225.

Csordas, T. (1990). Embodiment as a paradigm for anthropology. Ethos, 18(1), 5-47.

Csordas, T. (1999a). The body's career in anthropology. In H. Moore (Ed.), Anthropological Theory Today (pp. 172-187). Cambridge: Polity Press.

Csordas, T. (1999b). Embodiment and cultural phenomenology. In G. Weiss \& H. Haber (Eds.), Perspectives on embodiment: The intersections of nature and culture (pp. 143-162). New York: Routledge.

De Vries, R., Anderson, M.S., \& Martinson, B.C. (2006) Normal misbehaviour: Scientists talk about the ethics of research. Journal of Empirical Research in Human Research Ethics, 1, 43-50.

Fønnebø, V. (2013). Report: Alternative treatment in Norway 2012. [In Norwegian:Rapport: Alternativ behandling i Norge 2012.]

Gobo, G. (2008). Doing ethnography. Los Angeles: Sage Publications.

Grøn, L. (2004): Winds of change, bodies of persistence. Health promotion and lifestyle change in institutional and everyday contexts. Ph. D. thesis, Aarhus, Denmark: University of Aarhus.

Holmboe, O., Iversen, H. H., Sjetne, I. S., \& Skudal, K. E. (2011). The 2011 Commonwealth Fund survey among sicker adults: Results from a comparative survey in 11 countries. [In Norwegian: Commonwealth Fund-undersøkelsen i 2011 blant utvalgte pasientgrupper: Resultater fra en komparativ undersøkelse i 11 land.] Rapport 18/2011. Oslo: Nasjonalt kunnskapssenter for helsetjenesten.

Järvinen, M. (2005): Interview in an intractionist concept frame. [In Danish: Interview i en interaktionistisk begrepsramme.] In M.Järvinen og N. Mik-Meyer: Qualitative methods in an interactionst perspective. Interview, observations, and documents (pp. 27-48). (In Danish: Kvalitative metoder i et interaktionistisk perspektiv. Interview, observationer og dokumenter.) Copenhagen: Hans Reitzels Forlag.

Järvinen, M. \& Mik-Meyer, N. (2006). Introduction: Creating a client. [In Danish: Indledning: at skabe en klient.] In: Creating a client: Institutional identities in social work. [In Danish: At skabe en klient: institutionelle identiteter i socialt arbejde.] Copenhagen: Hans Reitzels Forlag.

Kleinman, A. (1980). Patients and healers in the context of culture: an exploration of the borderland between anthropology, medicine, and psychiatry. Berkeley: University of California Press.

Kiil, M. (2013). The paradox of Home: Understanding Northern Troms as a therapeutic landscape. In press.

Kuhnle, S. The Scandinavian welfare state in the global competitive society. [In Norwegian: Den skandinaviske velferdsstat i det globale konkurransesamfunn.] Article in Does the welfare state work? [In Norwegian: Virker velferdsstaten?] Stortingsmelding nr. 50 98/99- Utjamningsmeldinga.

Kvale, S. (2001). Interviews. An introduction to qualitative research interviewing. Thousand Oaks, California: Sage.

Mishler, E. G. (1986). Research Interviewing: Context and Narrative. Harvard University Press.

Rose, K. (1994). Unstructured and semi-structured interviewing. Nurse Researcher, 1(3), 23-32.

Rowe R. \& Calnan, M.(2006). Trust relations in healthcare: The new agenda. European Journal of Public Health, 16, 4-6.

Salamonsen, A., Kruse, T., \& Eriksen, S. H. (2012). Modes of embodiment in breast cancer patients using complementary and alternative medicine. Qualitative Health Research, 22(11), 1497-1512.

Salamonsen, A. (2013a). Doctor-patient communication and cancer patients' choice of alternative therapies as supplement or alternative to conventional care. Scandinavian Journal of Caring Sciences, 27, p. $70-76$.

Scambler, G. \& Britten, N. (2001). System, lifeworld and doctor-patient interaction, issues of trust in a changing world. In G. Scambler, (Ed.), Habermas, Critical Theory and Health. London: Routledge.

Spradley, J. 1980: Participant Observation. New York. Holt, Rhinehart and Winston.

Wagner, I. 1993: A web of fuzzy problems: Confronting the ethical issues. Communications of the ACM, 36, 94-101. 